\title{
United Nations Issues Guidelines to Minimize Risk of Invasive Species
}

$\mathrm{T}$

he United Nations Convention on Biological Diversity (CBD) has adopted new guidelines to prevent and control biological invasions by pets, aquarium and terrarium species, live bait, and live food. The new guidelines are largely based on input from the IUCN Species Survival Commission (SSC) Invasive Species Specialist Group (ISSG).

Invasive alien species are animals, plants, or other organisms introduced into places out of their natural range, where they become established and disperse, generating a negative impact on the local ecosystem and species.

Species invasions are a major and growing driver of biodiversity loss. Alien invasive species contributed to the extinc- tion of $54 \%$ of the 170 extinct animal species on the IUCN Red List for which the cause of extinction is known, and were the main cause for $20 \%$ of these extinctions. The introduction of alien invasive species is continuously increasing as a result of growing international trade.

Escape and release of pets, exotic caged animals, and species used as live bait or food are a major cause of biological invasions. Around 10,000 pets and companion species are present in Europe alone, including around 1,000 birds, several hundred mammals, around 2,000 species of reptiles and amphibians, as well as many invertebrates, including venomous spiders and scorpions.

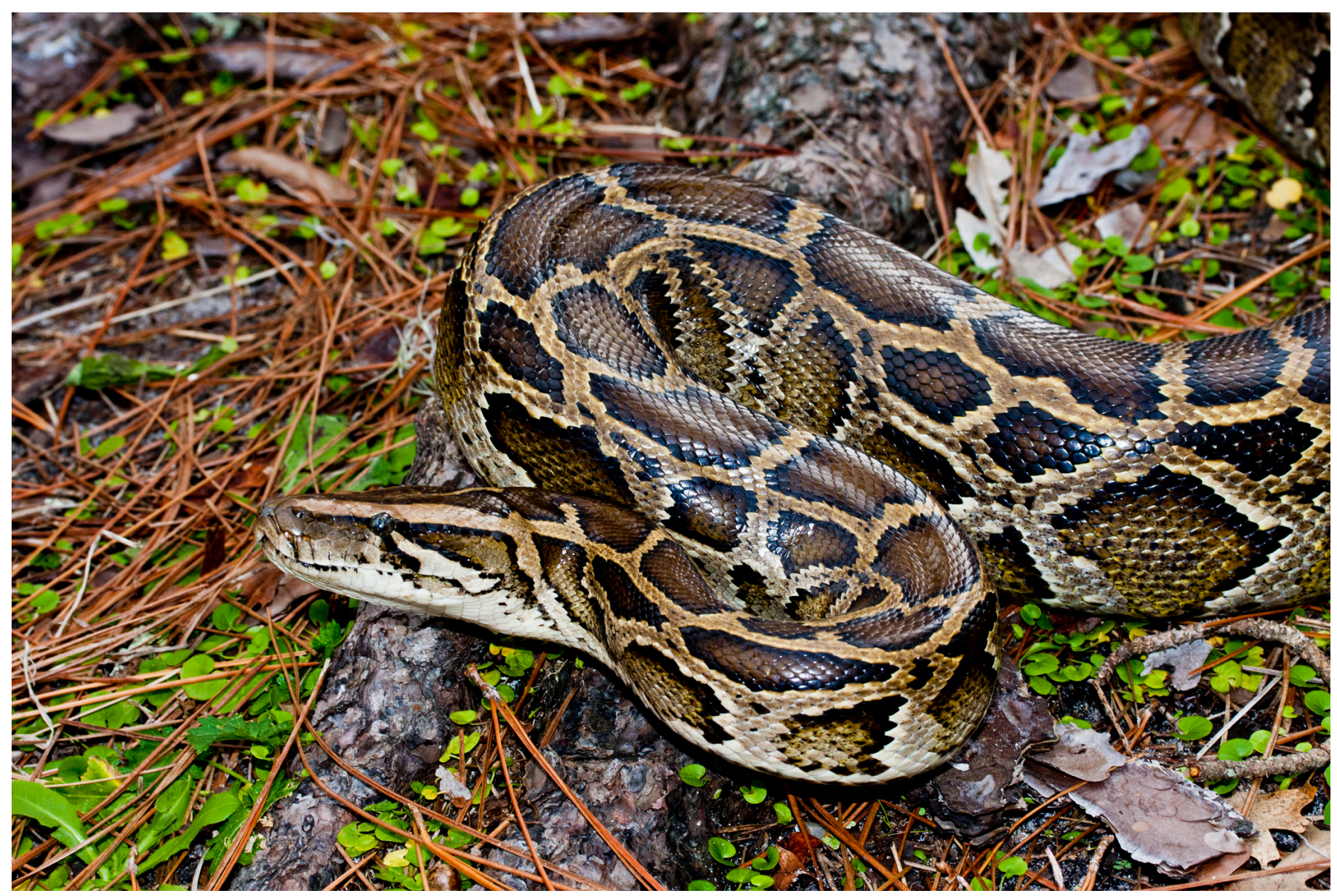

Burmese Pythons (Python bivittatus), now well established in southern Florida, have assumed top-predator status, eating native birds, mammals, and other reptiles, including many endangered species. Photograph (C) Kenneth L. Krysko. 
Domestic cats threaten bird, mammal, and reptile populations in many parts of the world, and invasive Grey Squirrels in Europe are outcompeting and transmitting disease to native Red Squirrels. Escaped exotic snakes, such as the Burmese Python in Florida and the Common Kingsnake on the Canary Islands, are damaging native wildlife. Population explosions of escaped or released pet rabbits are causing problems in many areas. Over 10,000 rabbits have invaded Helsinki, Finland, where they have taken over parks and graveyards, consuming flowers, loosening tree roots, and toppling tombstones.

Amphibians traded as pets or food are responsible for the spread of the deadly chytrid fungus that is causing the decline of wild amphibians globally. The Common Earthworm, a popular bait species, is detrimentally affecting the forest ecosystems of North America, and invasive crayfish species introduced for food are harming freshwater ecosystems in many areas. The Red Swamp Crayfish alone threatens two Critically Endangered and six Endangered species globally.

The CBD also asked Parties to compile and share information on alien invasive species and to make these data available to the databases managed by the IUCN SSC ISSG. The IUCN was called upon to continue providing technical support to the Convention, such as further elaborating methods to rank invasive species by the magnitude of their impacts, and continuing to carry out assessments on the positive and negative effects of the use of biocontrol agents to combat invasive species.

The guidelines were adopted on 10 October 2014 during the 12th meeting of the Conference of the Parties to the CBD (COP 12) in Pyeongchang, Republic of Korea. The guidelines are available at: www.cbd.int/doc/meetings/cop/ cop-12/insession/cop-12-L-05-en.pdf.

IUCN News Story; 14 October 2014 